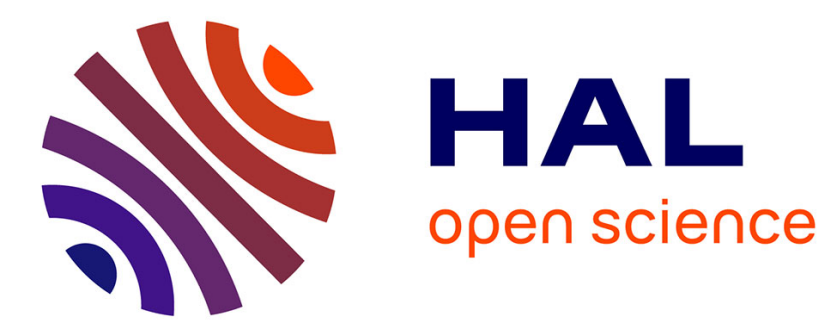

\title{
Study of variation of thermal expansion coefficients in carbon/epoxy laminated composite plates
}

Yasir Nawab, Frédéric Jacquemin, Pascal Casari, Nicolas Boyard, Yann

Borjon-Piron, Vincent Sobotka

\section{- To cite this version:}

Yasir Nawab, Frédéric Jacquemin, Pascal Casari, Nicolas Boyard, Yann Borjon-Piron, et al.. Study of variation of thermal expansion coefficients in carbon/epoxy laminated composite plates. Composites Part B: Engineering, 2013, 50, pp.144-149. 10.1016/j.compositesb.2013.02.002 . hal-01154412

\section{HAL Id: hal-01154412 \\ https://hal.science/hal-01154412}

Submitted on 26 Nov 2017

HAL is a multi-disciplinary open access archive for the deposit and dissemination of scientific research documents, whether they are published or not. The documents may come from teaching and research institutions in France or abroad, or from public or private research centers.
L'archive ouverte pluridisciplinaire $\mathbf{H A L}$, est destinée au dépôt et à la diffusion de documents scientifiques de niveau recherche, publiés ou non, émanant des établissements d'enseignement et de recherche français ou étrangers, des laboratoires publics ou privés. 


\title{
Study of variation of thermal expansion coefficients in carbon/epoxy laminated composite plates
}

\author{
Yasir Nawab a,b,c,*, Frédéric Jacquemin ${ }^{\mathrm{b}, *}$, Pascal Casari ${ }^{\mathrm{b}}$, Nicolas Boyard ${ }^{\mathrm{c}}$, Yann Borjon-Piron ${ }^{\mathrm{d}}$, \\ Vincent Sobotka ${ }^{c}$ \\ a Laboratoire d'Ondes et Milieux Complexes, UMR 6294 CNRS, University of Le Havre, 53 rue de Prony, BP 540, 76058 Le Havre, France \\ ${ }^{\mathrm{b}}$ Université de Nantes, Institut de Recherche en Génie Civil et Mécanique, UMR CNRS 6183, 37 boulevard de l'Université, BP 406,44600 SAINT-NAZAIRE, France \\ ' Université de Nantes, CNRS, Laboratoire de Thermocinétique de Nantes, UMR 6607, La Chantrerie, rue Christian Pauc, BP 50609, 44306 NANTES cedex 3, France \\ ${ }^{\mathrm{d}}$ Université de Nantes, CNRS, Institut des Matériaux Jean Rouxel, UMR 6502, 2 rue de la Houssinière, BP 32229, 44322 NANTES cedex 3, France
}

\begin{abstract}
Thermal expansion is an important property to define the end use application, and to model residual stresses and related problems in a composite part. Thus its accurate determination is essential. In laminated composites, this parameter depends largely on the orientation of fibres, fibre fraction, type of resin and reinforcement, etc. In this article, numerical results on the coefficients of thermal expansion (CTE) at different angles in the composite plates (having different stacking sequences of plies) found using finite element analysis are presented. Experimental values of these coefficients for [0/90] are found in satisfactory agreement with the simulations. Finally, a mathematical model is proposed for modelling these coefficients.
\end{abstract}

\section{Keywords:}

A. Polymer-matrix composites (PMCs)

B. Thermomechanical

C. Finite element analysis (FEA)

E. Thermosetting resin

Thermal expansion coefficients

\section{Introduction}

Polymer reinforced composites have become the premier choice for high-tech industries during the recent past, due to their favourable properties. A significant advantage of such materials is the choice of selection among several polymers and different types of reinforcement (fibre/fabric) to achieve required properties. Such materials undergo matrix cracking, delamination, fibre buckling, warpage, residual deformations [1,2] due to mismatched coefficients of thermal expansion of constituents, i.e. fibres and matrix [3]. Therefore, the knowledge of thermal expansion and/or contraction is essential to characterize the behaviour and end use application of composite materials [4]. Several authors have studied in-plane thermal coefficients of unidirectional composites $[5,6]$. Some of them [7-9] studied also the effect of orientation of fibres on these coefficients. But only a few authors reported the out of plane coefficients (through the thickness) of laminated composite. In one such study, Rogers et al. [10] reported that out of plane coefficients of cross-ply laminated composites were a little higher than in-plane coefficients. They related this difference to the

* Corresponding authors at: Laboratoire d'Ondes et Milieux Complexes, UMR 6294 CNRS, University of Le Havre, 53, rue de Prony, BP 540, 76058, Le Havre, France. Tel.: +33235217146 (Y. Nawab).

E-mail addresses: yasir.nawab@yahoo.com (Y. Nawab), frederic.jacquemin@ univ-nantes.fr (F. Jacquemin). presence of voids and anomalies of testing instrument. Akkerman [11] reported that the symmetric quasi-isotropic reinforcement had a lower in-plane thermal expansion and a higher in-plane stiffness as compared to out-of-plane thermal expansion and stiffness. He thought that this might be denoted as Poisson' effects. Otherwise, studies on the determination of thermal coefficients in different directions in laminated composite parts are rare.

In the present study, thermal expansion coefficients in different directions within the composite plates $\left(\left[0_{116}\right],[0 / 90]_{29 S}\right.$, and $[45 /$ $-45]_{29 s}$ ) were calculated numerically using finite element analysis. Homogenized thermomechanical properties of a composite ply, needed for these calculations, were found from the properties of resin and fibres using a self-consistent model [12]. The values of CTE of cross-ply composite in different directions were also determined experimentally and were compared with numerical results. Finally, a mathematical model, based on the strain matrix is proposed for modelling these coefficients.

The materials and dilatometery instrument used in this work are described in Section 2. The first subsection of results and discussion (Section 3 ) is on the determination of homogenized properties of composite from the properties of constituents. This is followed by the FEA and experimental results of CTE of composite samples. While in the last subsection an analytical model is presented for the determination of CTE. Finally, a conclusion is given at the end of this article. 


\section{Materials and methods}

For numerical calculations, laminated carbon/epoxy (M21/ T700 prepreg supplied by Hexcel Composites, dedicated to aeronautics) composite plates $(300 \mathrm{~mm} \times 300 \mathrm{~mm} \times 40 \mathrm{~mm})$ with stacking sequences [0], [0/90], and [ \pm 45$]$ were considered. For all these plates, CTEs were found at angles between $0^{\circ}$ and $180^{\circ}$, i.e. $0^{\circ}, 15^{\circ}, 30^{\circ}$, etc. in the $X Y, Y Z$ and $X Z$ plane (see Fig. 1). In $X Y Z$ plane, CTE was found along a vector making different angles along $Z$-axis such that its projection had been always a diagonal in the $X Y$ plane.

For experimental validation, cross-ply carbon/epoxy laminated plates were fabricated such as the fibre volume fraction was equal to $57 \%$. Each ply was $0.3 \mathrm{~mm}$ thick. The polymerization was carried out in an autoclave according to manufacturer provided curing cycle:

- Starting from the room temperature, heating up to $180^{\circ} \mathrm{C}$ at the rate of $3{ }^{\circ} \mathrm{C} / \mathrm{min}$.

- Maintaining at $180^{\circ} \mathrm{C}$ for $2 \mathrm{~h}$, and then cooling to room temperature at the rate of $5^{\circ} \mathrm{C} / \mathrm{min}$.

- A pressure of $0.5 \mathrm{MPa}$ was maintained during the curing.

Parallelepiped samples $(10 \mathrm{~mm} \times 10 \mathrm{~mm} \times 30-40 \mathrm{~mm})$ were cut from the composite plate, in the directions defined by a direction coefficient 0 or 1 , according to the axis $X, Y$ and $Z$ as presented in Table 1. For example, sample (100) was a parallelepiped cut along length of plate (X-axis). Similarly, sample (001) was cut along the $Z$-axis (thickness of plate). Sample (111) was cut such that it made an angle of $45^{\circ}$ (in space) with a diagonal in $X Y$ plane.

DI.24 ADAMEL LHOMARGY ${ }^{\circledR}$ dilatometer was used to measure thermal expansion of these samples, which were submitted to the following thermal cycle:

1. Heating from room temperature to $200^{\circ} \mathrm{C}$ at the rate of $2{ }^{\circ} \mathrm{C} /$ $\min$.

2. Cooling to $30^{\circ} \mathrm{C}$ at the rate of $2{ }^{\circ} \mathrm{C} / \mathrm{min}$.

3. Maintaining at $30^{\circ} \mathrm{C}$ for $80 \mathrm{~min}$.

This cycle was repeated two times for each sample. For each direction, two samples were tested and the results are averaged to obtain the final result.

\subsection{Description of the dilatometer}

DI.24 ADAMEL LHOMARGY ${ }^{\circledR}$ is a classical dilatometer (Fig. 2) used for the thermal expansion measurements of solids. It consists of an oven, an alumina sample support, thermocouples, and LVDT sensors.
Table 1

Direction codes of samples.

\begin{tabular}{ll}
\hline Code & Direction \\
\hline $\mathrm{S}(100)$ & Along $X$-axis \\
$\mathrm{S}(010)$ & Along $Y$-axis \\
$\mathrm{S}(001)$ & Along $Z$-axis \\
$\mathrm{S}(110)$ & Diagonal in $X Y$ plane \\
$\mathrm{S}(011)$ & Diagonal in $Y Z$ plane \\
$\mathrm{S}(101)$ & Diagonal in $X Z$ plane \\
$\mathrm{S}(111)$ & $\begin{array}{l}\text { At an angle of } 45^{\circ} \text { (in the space) with its projection, which is } \\
\\
\text { diagonal in } X Y \text { plane }\end{array}$ \\
\hline
\end{tabular}

- Oven consists of a heater based on a silicon carbide resistor, which can heat the sample from room temperature to $1600^{\circ} \mathrm{C}$. The oven can be moved on a rail to facilitate the sample placement in it.

- Alumina support, for placing the samples of dimensions 10$50 \mathrm{~mm}$ long in the oven. The cross-section of the sample can be up to $10 \mathrm{~mm} \times 10 \mathrm{~mm}$.

- Temperature is recorded with two thermocouples. The first one is located in the alumina support for the measurement of sample temperature, and the second one in the centre of the oven to detect and control the heating temperature.

- The head consist of a LVDT (linear variable differential transformer) type displacement sensor, and two screws for adjusting the zero length and initial load on the sample.

The sample placed on an alumina support was held with a pressing bar. This bar could be positioned with two screws to adjust zero strain and initial load on the sample (1 $\mathrm{mm}$ in our case), while checking these values in the interface of Labview ${ }^{\circledR}$ software. This bar is linked to the LVDT sensor. The length variations during the heating/cooling are recorded and sent to the acquisition system. The output data contains time, elongation of the sample, and temperature. The slope of the elongation versus temperature graph when divided by initial thickness provides the coefficient of thermal expansion. The accuracy of CTE measured by this instrument is equal to $\pm 0.1 \times 10^{-6} \mathrm{~K}^{-1}$.

\section{Results and discussion}

\subsection{Determination of homogenized properties of a composite ply}

In order to find homogenized properties of composite plate, a self-consistent model based on the mathematical formalism proposed by Kröner [13] and Eshelby [14] is used. A composite ply is assumed as an infinite medium in which ellipsoidal inclusions (fibres) are embedded.

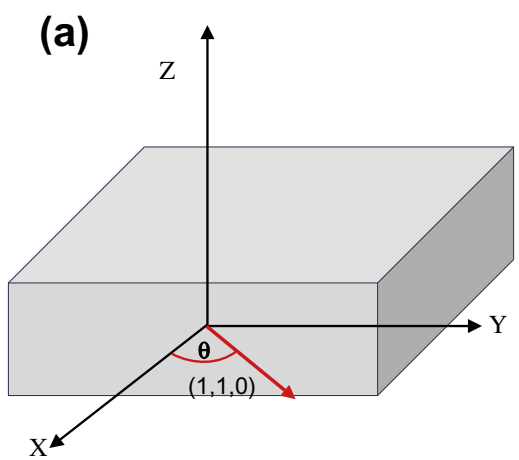

Fig. 1. Illustration of directions in $X Y$ (a) and $X Y Z$ (b) planes of composite plate at which CTEs were determined. 


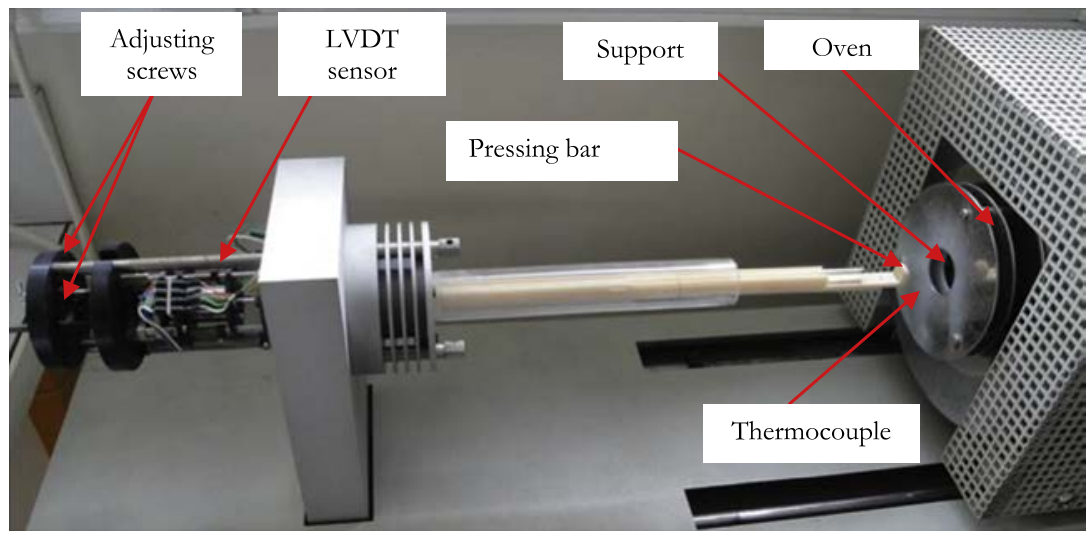

Fig. 2. DI.24 (ADAMEL LHOMARGY ${ }^{\circledR}$ ) dilatometer.

The properties of this medium are found by applying a homogenization technique on the fibres and matrix. The material is investigated at two different scales (fibre and composite) for the needs of micromechanical modelling. The properties of the ply at the macroscopic level, denoted using superscript ' $I$ ' are calculated from the properties of fibres and matrix (microscopic level) denoted by ' $f$ ' and ' $m$ ' respectively [15]. The microscopic and macroscopic residual stress generated in the ply due to the temperature change can be found using the thermo-elastic constitutive equation:

$\overline{\bar{\sigma}}=\stackrel{\bar{C}}{C}(\stackrel{\overline{\bar{\varepsilon}}}{\bar{\varepsilon}}-\stackrel{\overline{ }}{\mathrm{CTE}} \Delta T)$

The residual stress and strain are related by the scale transition relation (2) presented by Eshelby:

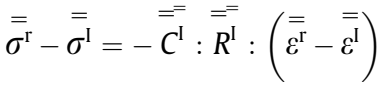

Here ' $r$ ' stands for fibre ( $f$ ) or matrix $(m) . R^{\mathrm{I}}$ is the reaction tensor and its value can be found by the expression:

$\left.\overline{\overline{R^{\mathrm{I}}}}=\overline{\overline{\mathrm{C}^{-1}}}-\overline{\bar{E}}\right): \overline{\overline{E^{-1}}}$

$E$ is the Morris tensor which expresses the dependence of reaction tensor on morphology of constituents.

Macroscopic stress and strain and the microscopic stresses and strains of constituents can be related using the (Eq. (4)) reported by Hill [16]:

$$
\begin{aligned}
& \left\langle\overline{\overline{\sigma^{\mathrm{r}}}}\right\rangle_{r=f, m}={\overline{\sigma^{\mathrm{I}}}}^{\mathrm{I}} \\
& \left\langle\overline{\overline{\varepsilon^{\mathrm{r}}}}\right\rangle_{r=f, m}=\overline{\overline{\varepsilon^{\mathrm{I}}}}
\end{aligned}
$$

The self-consistent model allows the determination of macroscopic elasticity tensor, and coefficients of thermal expansion of ply from the mechanical, and thermal properties of the constituents. The relation (5) gives the classical expression of rigidity:

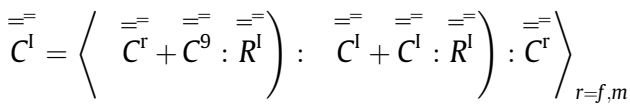

$C^{\mathrm{l}}$ was determined by (5) using iterative method. Assuming, the same temperature at both scales, i.e. $\Delta T^{\mathrm{r}}=\Delta T^{\mathrm{I}}$, the self-consistent model provides the tensor of the homogenized coefficient of thermal expansion of the ply (6):

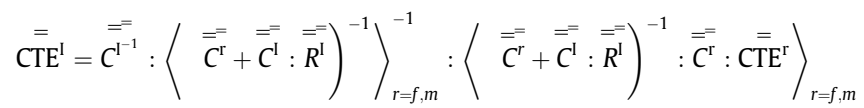

For the cured glassy resin following properties from literature [17] are used: Young's modulus $E^{\mathrm{m}}=1.37 \mathrm{GPa}$, Poisson ratio $v^{\mathrm{m}}=0.35, \mathrm{CTE}^{\mathrm{m}}=44.9 \times 10^{-6} \mathrm{~K}^{-1}$. Whereas, the properties of fibres are given in Table 2 .

Effective properties of a cured composite ply $\left(0^{\circ}\right)$ found from the properties of cured resin, and fibres using self-consistent model are given in Table 3. These were further used to determine the properties of plies according to their orientations, and then used as an input to FE code.

\subsection{Finite element analysis results}

A static FE analysis was carried out in structural mechanics module of software COMSOL ${ }^{\circledR}$ Multiphysics. Several layers (plies) were stacked over each other to get required sample length (about $35 \mathrm{~mm}$ ). Properties of each ply (calculated using self-consistent model) were determined according to its orientation and were fed into the software. It was assumed that temperature of sample at the beginning of the test was uniform and was equal to room temperature $\left(T_{\text {ref }}=20^{\circ} \mathrm{C}\right)$. The body was supposed under no mechanical stress. The sample was constrained at only two nodes to prevent the model to twist. Thermal strain along the sample length was calculated for a heating of $\Delta T=100^{\circ} \mathrm{C}$ above room temperature considering that the sample is purely elastic. This strain was uniform throughout the sample body. From this result CTE was calculated. A little variation of strain was observed near the edges along the length of [0/90] and [ \pm 45$]$, which was assumed because of interaction between plies of different orientations.

\subsubsection{CTE Variation in XY plane for different stacking sequences}

Since the fibers have lower CTE compares to CTE of resin, they hinder the thermal expansion of resin on heating. This hindrance depends on the type of fibres and their orientation in composite part. In Fig. 3, schematic views of different stacking sequences are presented for better understanding.

\section{Table 2}

Mechanical and thermomechanical properties of fibres.

\begin{tabular}{llll}
\hline Property & Value & Property & Value \\
\hline$E_{1}(\mathrm{GPa})$ & 230 & $G_{12}(\mathrm{GPa})$ & 27.6 \\
$E_{2}, E_{3}(\mathrm{GPa})$ & 20.7 & $G_{23}(\mathrm{GPa})$ & 6.89 \\
$v_{12}, v_{13}$ & 0.2 & $\mathrm{CTE}_{1}, \mathrm{CTE}_{2}\left(10^{-6} \mathrm{~K}^{-1}\right)$ & $-3.8,20$ \\
\hline
\end{tabular}


Table 3

Effective properties of a cured (glassy) carbon/epoxy ply.

\begin{tabular}{lllllll}
\hline Property & $\mathrm{CTE}_{1}\left(\mathrm{~K}^{-1}\right)$ & $\mathrm{CTE}_{2}\left(\mathrm{~K}^{-1}\right)$ & $\begin{array}{l}E_{1} \\
(\mathrm{GPa})\end{array}$ & $\begin{array}{l}E_{2} \\
(\mathrm{GPa})\end{array}$ & $G_{12}(\mathrm{GPa})$ & $v_{12}$ \\
\hline Value & $0.21 \times 10^{-6}$ & $29.8 \times 10^{-6}$ & 131.2 & 5.63 & 6.40 & 0.25 \\
\hline
\end{tabular}

Young's modulus in a certain direction can also be used as an indicator of hinderance of fibres to thermal expansion in that direction. Higher is the Young's modulus, lower will be the thermal expansion. Young's modulus of [0] stacking sequence composite is highest along $X$-axis (along fibre's length) and lowest along $Y$-axis (perpendicular to fibre's length). Therefore, $\mathrm{CTE}_{1}$ should have a minimum, and $\mathrm{CTE}_{2}$ a maximum value. $\mathrm{FE}$ analysis provides such expected results, as shown in Fig. 4a.

From the $\mathrm{FE}$ calculation, $\mathrm{CTE}_{1}$ (at angle $0^{\circ}$ with $X$-axis) was found equal to $0.218 \times 10^{-6} \mathrm{~K}^{-1}$, which increased with respect to angle with $X$-axis, and became maximum along $Y$-axis $\left(\mathrm{CTE}_{2}=40.7 \times 10^{-6} \mathrm{~K}^{-1}\right)$.

The values of both $\mathrm{CTE}_{1}$ and $\mathrm{CTE}_{2}$ of [0/90] (Fig. 4b) are minimum, since Young's modulus along $X$ and $Y$-axis is maximum in this stacking system. Moving from $0^{\circ}$ to $45^{\circ}$, CTE increased and became maximal at $45^{\circ}$ with $X$-axis, since Young's modulus is minimal in this direction (see Fig. $4 \mathrm{~b}$ ).

Due to the orientation of fibres, Young's modulus along both $X$ and $Y$ axis is minimum in [ \pm 45$]$ stacking sequence. Therefore, value of $\mathrm{CTE}_{1}$ and $\mathrm{CTE}_{2}$ are maximum (Fig. 4b). For this stacking sequence, value of CTE is minimal at $45^{\circ}$ because the fibers are parallel to this direction (Young's modulus is the highest).

It can be noted that in the $X Y$ plane, values of CTE of [0] are very high as compared to CTE of [0/90] and [ \pm 45$]$. The extreme values of CTE of $[0 / 90]$ and $[ \pm 45]$ are 2.22 and $3.19 \times 10^{-6} \mathrm{~K}^{-1}$ with a range of $0.94 \times 10^{-6} \mathrm{~K}^{-1}$. This range is very small as compared to that of [0], which is equal to $40.5 \times 10^{-6} \mathrm{~K}^{-1}$.

Since the values of CTE of [0/90] and $[ \pm 45]$ are very close to each other in comparison to [0], it can be assumed that the in-plane (XY plane) thermal expansion behaviour of $[0 / 90]$ and $[ \pm 45]$ is almost same.

\subsubsection{CTE Variation in $X Z$ plane for different stacking sequences}

Fig. 5 shows the variation of CTE in the $X Z$ plane versus angle with the $X$-axis. CTE for all the stacking sequences is minimal along $X$-axis. It increased with increase in angle and became maximal along $Z$-axis $\left(\mathrm{CTE}_{3}\right)$. It is observed that for [0] stacking sequence plate, $\mathrm{CTE}_{2}=\mathrm{CTE}_{3}=40 \times 10^{-6} \mathrm{~K}^{-1}$, which is in agreement with the literature. As per our understanding, value of $\mathrm{CTE}_{3}$ depends on the values of CTE in $X Y$ plane. If resin is more constrained in $X Y$ plane by fibres, it will try to expand along $Z$-axis, since no fibrous binding is present among the plies in this direction. By FE calculations, the values of $\mathrm{CTE}_{3}$ of $[0 / 90],[ \pm 45]$ is found higher than [0]. This can be explained considering the above mentioned hypothesis.

\subsubsection{CTE Variation in $X Y Z$ plane for different stacking sequences}

In 3D, we studied the CTE of samples (in XYZ plane, see Fig. 1b) that make a variable angle with its projection in $X Y$ plane such that
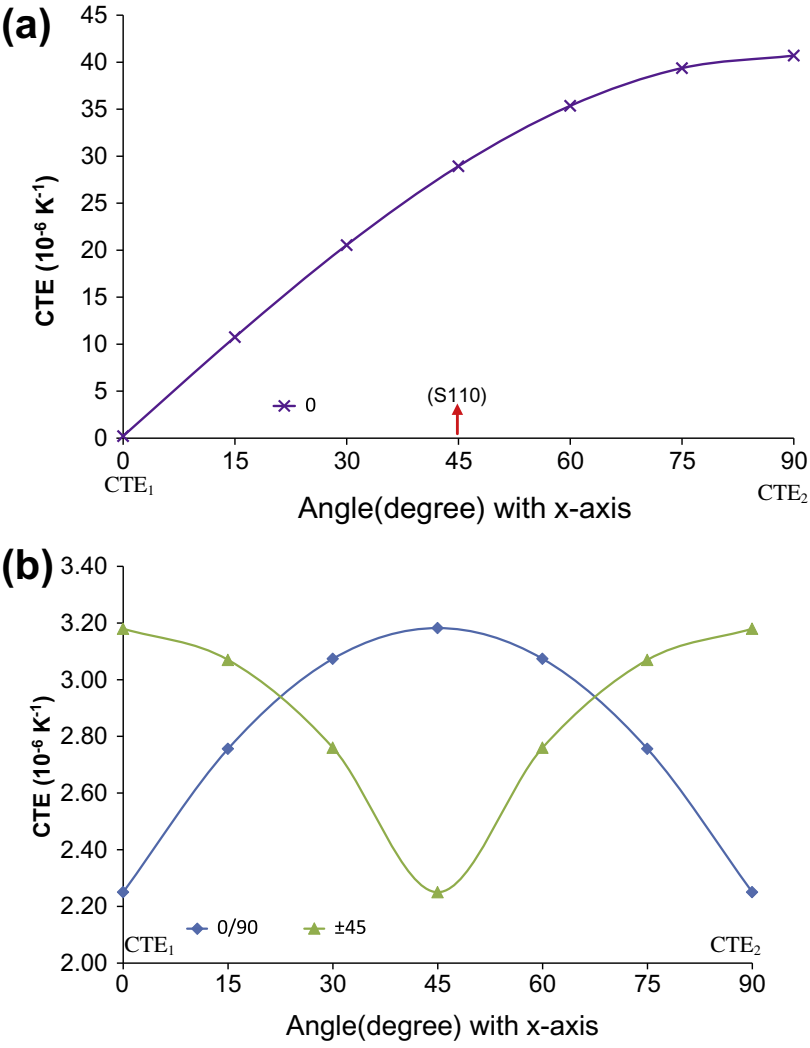

Fig. 4. Computed CTEs at different angles in $X Y$ plane for different stacking sequences (a) [0] stacking sequence (b) [0/90], and [ \pm 45$]$ stacking sequence.

the projection of this sample in $X Y$ plane is always diagonal. The variation of CTE of such samples is more difficult to explain due to complex orientation of fibres.

In Fig. 6, CTEs ( $X Y Z$ plane) calculated from global normal strains of samples having stacking sequences of [0], [0/90], and [ \pm 45$]$ are plotted versus their angle with diagonal in $X Y$ plane. The strain in this direction is resultant of strains along $X, Y$ and $Z$-directions.

It can be noted that for all stacking sequences, CTEs has a minimum value at $\theta=0^{\circ}$ (along the diagonal in $X Y$ plane). This seems logical because fibres are laid down in the $X Y$ plane and they resist the expansion of material on heating. For $[0 / 90]$ and [ \pm 45$]$, with an increase in angle, CTE increases too and become maximum at $\theta=90^{\circ}$ (along $Z$-axis).

\subsection{Experimental results}

For experimental validation of numerical results, [0/90] composite plate was selected as it is classically studied in academics. In Fig. 7 , strain $\left(\Delta e / e_{0}\right)$ responses of composite samples $(0,0,1)$ and $(1,1,1)$ during the heating ramps are plotted versus temperature. If $e$ is the length after heating for temperature $\Delta T$, and $e_{0}$ is

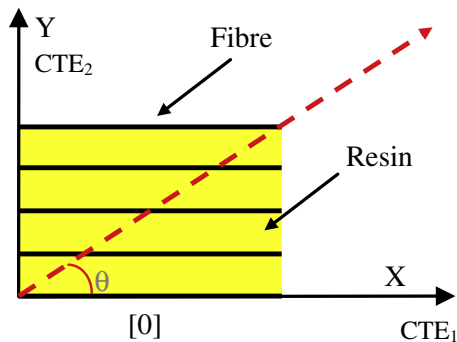

$\mathrm{CTE}_{1}$

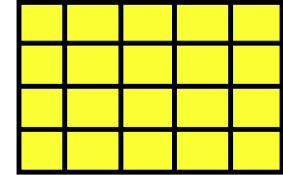

[0/90]

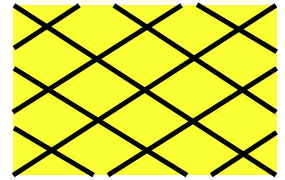

$[ \pm 45]$

Fig. 3. $X Y$ plane (top view) of composite plates with different stacking sequences 


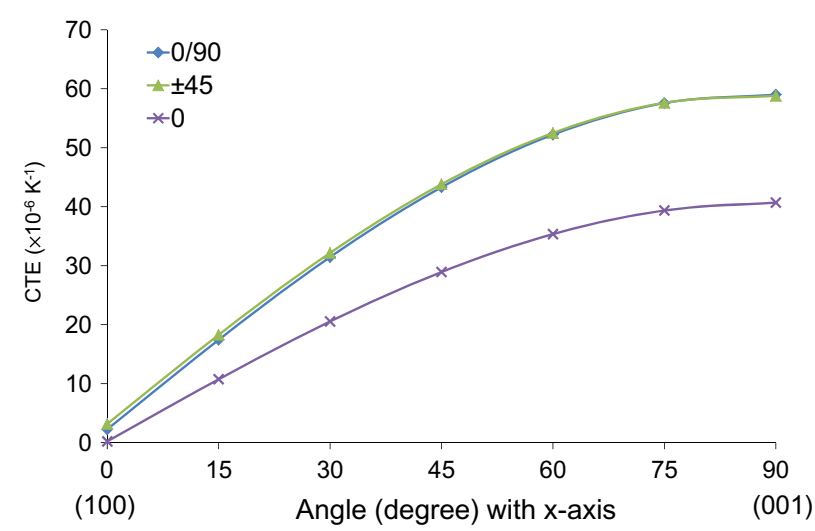

Fig. 5. Computed CTE at different angles in $X Z$ plane for various stacking sequences.

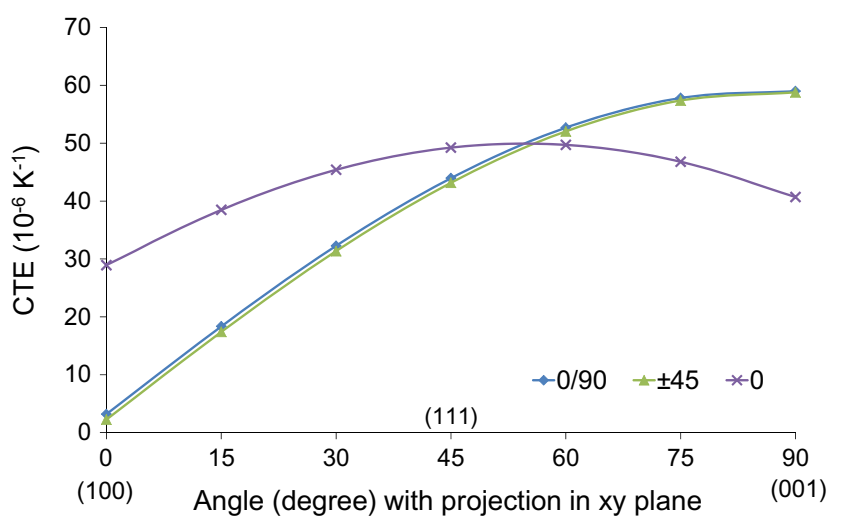

Fig. 6. CTE at different angles in space (XYZ plane) for various stacking sequences.

the initial length, then $\Delta e=e-e_{0}$. Slope of a graph gives the corresponding coefficient of thermal expansion

$\left(\mathrm{CTE}=\frac{1}{e_{0}}\left(\frac{\partial e}{\partial T}\right)\right)$.

A change in the slope of strain-temperature graphs can be observed on reaching the temperature zone $\left(170-180^{\circ} \mathrm{C}\right)$ as shown in Fig. 7. This change occurs in the zone of glass transition of composite sample $\left(\mathrm{Tg}=180.6^{\circ} \mathrm{C}\right.$ found by DSC for fully cured sample). Therefore, it can be concluded that the change in slope is due to glass transition of composite from glassy to rubbery state. It can also be observed that slope of graph of sample (001) is higher than the slope of sample (111), both below and above $\mathrm{Tg}$, respectively. It means that CTE of sample (001) has a higher value than the CTE of sample (111). Similar behaviour can be observed for CTEs above Tg.

Fig. 8 shows the comparison of CTEs below and above Tg of all the tested samples. It can be noted that in-plane CTEs, in $X Y$ plane (i.e. $(100),(010)$ and (110), are very small as compared to other coefficients. The out-of-plane coefficients at $45^{\circ}$ in $X Z$ and $Y Z$ planes (( 101$)$ and $(011)$ ) have almost the same values (about $4 \times 10^{-5} \mathrm{~K}^{-1}$ ). The CTE of sample (111) has a slightly higher value $\left(4.56 \times 10^{-5} \mathrm{~K}^{-1}\right)$. The value of CTE of sample (001) was found equal to $68.1 \times 10^{-6} \mathrm{~K}^{-1}$ and is the highest one. Similar behaviour was observed for the thermal coefficients above the glass temperature.

FE calculation results for [0/90] are also presented in Fig. 8 for comparison. It can be observed that both results are in agreement (a difference of 6-7\%) within acceptable limits.

\subsection{Analytical modelling}

The next step was to propose an analytical model for prediction of CTE, depending on the orientation of fibres. At first, an attempt

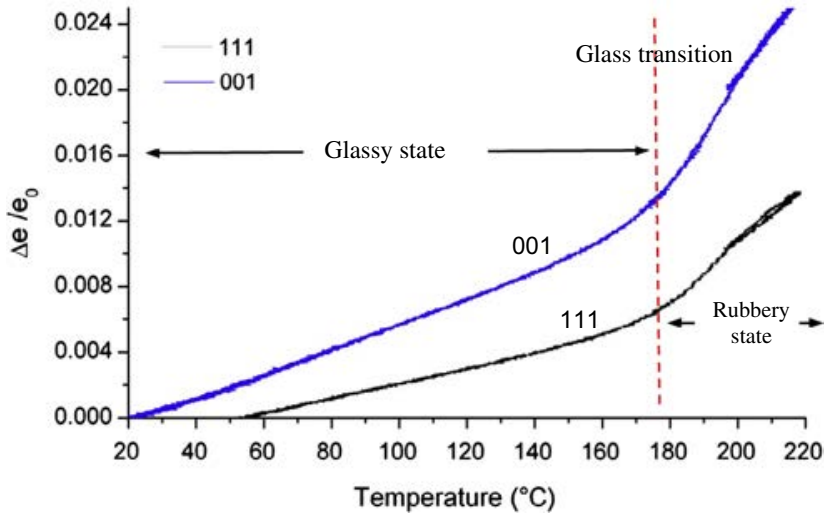

Fig. 7. Thermal strain versus temperature response of samples 001 and 111.

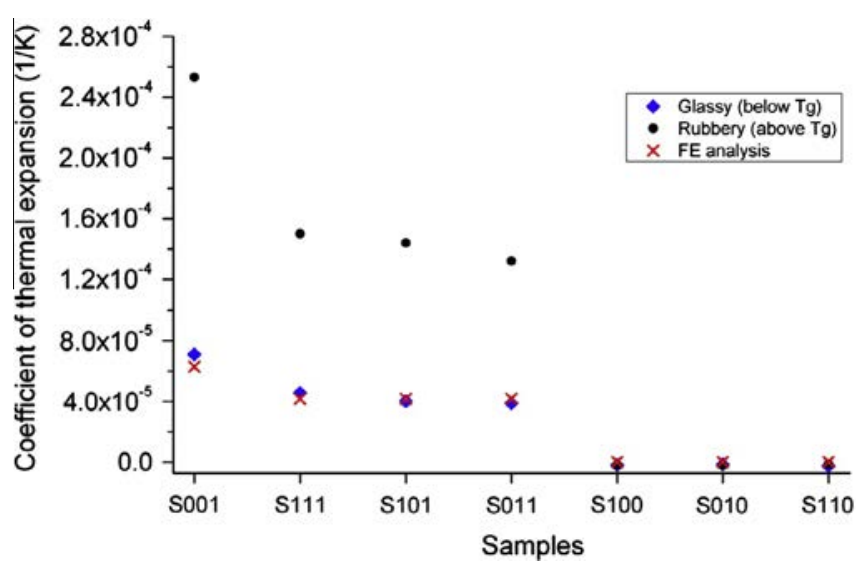

Fig. 8. Linear coefficients of thermal expansion $\left(\mathrm{K}^{-1}\right)$.

was made to use the strain matrix to calculate the $\mathrm{CTE}_{111}$ from the experimental values of other (six) in-plane CTEs, which was then compared with the experimental value. Consider $\vec{\varepsilon}=\vec{\varepsilon}_{x y z}$ is a strain vector in space that makes an angle of $45^{\circ}$ with diagonal in the $X Y$ plane:

Multiplying this vector with a unit vector $\vec{n}$ leads to:

$\varepsilon \vec{n} \cdot \vec{n}=\left[\begin{array}{l}\frac{\varepsilon_{x x}}{\sqrt{3}}+\frac{\varepsilon_{x y}}{\sqrt{3}}+\frac{\varepsilon_{x z}}{\sqrt{3}} \\ \frac{\varepsilon_{x y}}{\sqrt{3}}+\frac{\varepsilon_{y y}}{\sqrt{3}}+\frac{\varepsilon_{y z}}{\sqrt{3}} \\ \frac{\varepsilon_{x z}}{\sqrt{3}}+\frac{\varepsilon_{y z}}{\sqrt{3}}+\frac{\varepsilon_{z z}}{\sqrt{3}}\end{array}\right] \cdot\left[\begin{array}{c}\frac{1}{\sqrt{3}} \\ \frac{1}{\sqrt{3}} \\ \frac{1}{\sqrt{3}}\end{array}\right]$

This unit vector in $X Y Z$ plane in direction described above will be equal to:

$\vec{n}=\left[\begin{array}{c}\frac{1}{\sqrt{3}} \\ \frac{1}{\sqrt{3}} \\ \frac{1}{\sqrt{3}}\end{array}\right]$

For $1 \mathrm{~K}$ rise in temperature, strain in a direction will be equal to CTE in that direction, and Eq. (7) can be written as:

$\mathrm{CTE}_{111}=\left[\begin{array}{l}\frac{\mathrm{CTE}_{100}}{\sqrt{3}}+\frac{\varepsilon_{x y}}{\sqrt{3}}+\frac{\varepsilon_{x z}}{\sqrt{3}} \\ \frac{\varepsilon_{x y}}{\sqrt{3}}+\frac{\mathrm{CTE}_{010}}{\sqrt{3}}+\frac{\varepsilon_{y z}}{\sqrt{3}} \\ \frac{\varepsilon_{x z}}{\sqrt{3}}+\frac{\varepsilon_{y z}}{\sqrt{3}}+\frac{\mathrm{CTE}_{001}}{\sqrt{3}}\end{array}\right] \cdot\left[\begin{array}{c}\frac{1}{\sqrt{3}} \\ \frac{1}{\sqrt{3}} \\ \frac{1}{\sqrt{3}}\end{array}\right]$

The values $\varepsilon_{x y}, \varepsilon_{y z}, \varepsilon_{x z}$ can be found by solving the strain matrices in their respective planes. By solving (9), the value of CTE for sample 111 was found equal to $30 \times 10^{-6} \mathrm{~K}^{-1}$. The experimental value ranges from $37 \times 10^{-6}$ to $44 \times 10^{-6} \mathrm{~K}^{-1}$. The results show that a 
mathematical model based on above approach may be suitable for such estimations. The model can be improved by considering the other thermophysical phenomena such as $\mathrm{Tg}$.

\section{Conclusion}

In the present study, the effect of fibre orientation on thermal expansion of carbon/epoxy laminated composite plates is studied. It is found that CTE varies in $X Y$ and $X Z$ planes with respect to angle with the $X$-axis.

For [0] composite, variation of CTE with angle is equal in $X Y$ and $Y Z$ planes such that at a given angle $\mathrm{CTE}_{2}=\mathrm{CTE}_{3}$. For other sequences values of CTE in $X Z$ plane are higher as compared to CTE in $X Y$ plane. For all stacking sequences other than [0], value of $\mathrm{CTE}_{3}$ is greater than the value of CTE in any other direction. The results of FE simulations are confirmed by experimental determination of CTE of [0/90] composite.

As expected, it was observed experimentally that $\mathrm{Tg}$ has a significant effect on CTE of composite. A mathematical model, based on the strain matrix is proposed for modelling these coefficients. However, more experiments at different orientations are required to improve this model.

\section{References}

[1] Gigliottia M, Molimard J, Jacquemin F, Vautrin A. On the nonlinear deformations of thin unsymmetric $0 / 90$ composite plates under hygrothermal loads. Compos Part A: Appl Sci Manuf 2006;37(4):624-9.

[2] Kim H-S, Yoo S-H, Chang S-H. In situ monitoring of the strain evolution and curing reaction of composite laminates to reduce the thermal residual stress using FBG sensor and dielectrometry. Compos Part B: Eng 2013; 44(1):446-52.
[3] Nawab Y, Tardif X, Boyard N, Sobotka V, Casari P, Jacquemin F. Determination and modelling of the cure shrinkage of epoxy vinylester resin and associated composites by considering thermal gradients. Compos Sci Technol 2012;73:81-7.

[4] Nawab Y, Jacquemin F, Casari P, Boyard N, Sobotka V. Evolution of chemical and thermal curvatures in thermoset laminated composite plates during the fabrication process. J Compos Mater 2013;47(3):327-39.

[5] Ishikawa T, Koyama K, Kobayashi S. Thermal expansion coefficients of unidirectional composites. J Compos Mater 1978;12(2):153-68.

[6] Kobayashi S, Ishikawa T. Elastic properties of unidirectional fiber-reinforced composites. Compos Mater Struct 1974(3).

[7] Craft WJ, Christensen RM. Coefficient of thermal expansion for composites with randomly oriented fibers. J Compos Mater 1981;15(1):2-20.

[8] Tezvergil A, Lassila LVJ, Vallittu PK. The effect of fiber orientation on the thermal expansion coefficients of fiber-reinforced composites. Dental Mater Off Publ Acad Dental Mater 2003;19(6):471-7.

[9] Fahmy AA, Ragai AN. Thermal expansion of graphite epoxy composites. J Appl Phys 1970;41(13):5112-5.

[10] Rogers KF, Phillips LN, Kingston-Lee DM, Yates B, Overy MJ, Sargent JP, et al. The thermal expansion of carbon fibre-reinforced plastics. J Mater Sci 1977;12(4):718-34.

[11] Akkerman R. On the properties of quasi-isotropic laminates. Compos Part B: Eng 2002;33(2):133-40.

[12] Abou Msallem Y, Jacquemin F, Poitou A. Residual stresses formation during the manufacturing process of epoxy matrix composites: resin yield stress and anisotropic chemical shrinkage. Int J Mater Forming 2010;3(Suppl 2):1363-72.

[13] Kröner E. Berechnung der elastischen konstanten des vielkristalls aus den konstanten des einkristalls. Zeitschrift für Physik A Hadrons and Nuclei 1958;151(4):504-18.

[14] Eshelby JD. The determination of the elastic field of an ellipsoidal inclusion, and related problems. Proc $\mathrm{R}$ Soc London Ser A Math Phys Sci 1957;241(1226):376-96.

[15] Jacquemin F, Freour S, Guillen R. A Hygroelastic self-consistent model for fiberreinforced Composites. J Reinf Plast Compos 2005;24(5):485-502.

[16] Hill R. The essential structure of constitutive laws for metal composites and polycrystals. J Mech Phys Solids. 1967;15(2):79-95.

[17] Abou Msallem Y, Jacquemin F, Boyard N, Poitou A, Delaunay D, Chatel S. Material characterization and residual stresses simulation during the manufacturing process of epoxy matrix composites. Compos Part A: Appl Sci Manuf 2010;41(1):108-15. 